\title{
ANALYSIS OF THE PRE-ROTATION ENGINE LOADS IN THE AUTOGYRO
}

\author{
Zbigniew Czyż', Tomasz Łusiak², Daniel Czyz' ${ }^{1}$, Dariusz Kasperek ${ }^{3}$
}

1 Department of Thermodynamics, Fluid Mechanics and Aviation Propulsion Systems, Faculty of Mechanical Engineering, Lublin University of Technology, 36 Nadbystrzycka Str., 20-618 Lublin, Poland, e-mail: z.czyz@ pollub.pl, czyzdaniel21@gmail.com

2 Department of Airframe and Engine, Polish Air Force Academy, 35 Dywizjonu 303 Str., 08-521 Dęblin, Poland, e-mail: t.lusiak@pollub.pl

3 URSUS S.A. Lublin, 7 Frezerów Str., 20-209 Lublin, Poland, e-mail: dariusz.kasperek@ursus.com

Received: 2016.05.11

Accepted: 2016.07.04

Published: 2016.09.01

\begin{abstract}
The paper presents the analyzes of the pre-rotation engine loads in the Taurus autogyro manufactured by Aviation Artur Trendak from Poland. Based on the NACA-9 H-12 airfoil characteristics of the drag coefficient, on which the rotor blade was made, forces acting on the rotor during pre-rotation have been calculated. The paper presents the characteristics of the drag coefficient as a function of angle of attack for $\mathrm{Re}=$ $1,800,000$ and $\mathrm{Re}=2,600,000$. For the speed range of 0 to $400 \mathrm{rpm}$ torque resulting from the drag forces and the power required to drive the rotor were calculated.
\end{abstract}

Keywords: pre-rotation, main rotor, aerodynamics, aerodynamic loads, gyroplane, autogyro.

\section{INTRODUCTION}

Pre-rotation is the coupling of the engine which drives the pusher propeller and the main rotor. This combination is designed for the drive of the main rotor for particular rotational speeds to have a short start. During takeoff the main rotor of the gyroplane must achieve the required rotational speed at which the lift force generated enables its separation from the wall. The gyroplane main rotor acts thanks to the phenomenon of autorotation, which is self-propelled by an airfoil through it [1]. The airflow is generated by the flight speed of the aircraft. If the gyrocopter is equipped with an additional pre-rotation system the distance that the aircraft must travel on the runway until its separation from the wall due to the increase in the lifting force is several times shorter than a takeoff without pre-rotation. Initial time of increasing the rotor and reached rotational speed have a significant impact on the time and length of a take-off road of a gyroplane [2].
The simplest type of the pre-rotation rotor system for gyrocopters is manual pre-rotation of the impeller. This method is used in amateur structures. A safe untwisting rotor achieves low speed, approx. 4-10 rpm. Having such a small value of rotational speed, the gyroplane needs a long way to take off. Along this way, it is necessary to set the rotor at a high angle of attack in order to obtain parameters that are appropriate for takeoff conditions. Systems of pre-rotation use different solutions which include:

- a flexible shaft,

- a hydraulic or pneumatic engine,

- an electric engine,

- reactionary propulsion,

- a rigid shaft.

This work is to check the possibility of using the pre-rotation system equipped with an electric motor. In the existing solutions of constructions, the rotor is driven from $0 \mathrm{rpm}$ to approx. 150-200 $\mathrm{rpm}$. The optimum rotor speed reaches approx. 40 $60 \%$ of nominal speed of the main drive motor [2]. 


\section{RESEARCH OBJECT}

A gyroplane to which a system of a prerotation rotor is being developed is Taurus. Taurus is a multi-tasking gyroplane equipped with 3 seats $(1+2)$ produced by Aviation Artur Trendak\&Son [3]. Figure 1 shows the visualization of Taurus gyroplane.

It is a gyroplane with a curb weight of $285 \mathrm{~kg}$ and a maximum take-off weight of $600 \mathrm{~kg}$. It is equipped with an internal combustion engine CA 912 ULT (RST) $135 \mathrm{hp}$. The diameter of its rotor is $8.8 \mathrm{~m}$. The basic performance parameters of the Taurus are shown in Table 1.

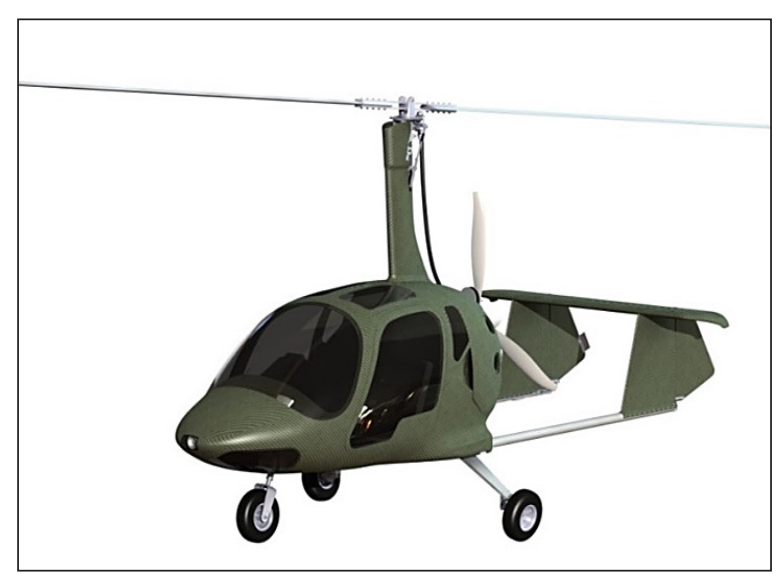

Fig. 1. Taurus gyroplane [3]
Table 1. Basic performance of the Taurus [3]

\begin{tabular}{|l|c|}
\hline \multicolumn{2}{|c|}{ Performance parameters } \\
\hline Minimum speed & $50 \mathrm{~km} / \mathrm{h}$ \\
\hline Cruising speed & $130 \mathrm{~km} / \mathrm{h}$ \\
\hline Maximum speed & $170 \mathrm{~km} / \mathrm{h}$ \\
\hline Impassable speed & $210 \mathrm{~km} / \mathrm{h}$ \\
\hline Rate of climb & $4.1 \mathrm{~m} / \mathrm{s}$ \\
\hline The minimum length of the runway & $150 \mathrm{~m}$ \\
\hline The minimum length the landing distance & $0-5 \mathrm{~m}$ \\
\hline Maximum ceiling flight & $4000 \mathrm{~m}$ \\
\hline Fuel consumption & $25 \mathrm{l} / \mathrm{h}$ \\
\hline Endurance & $4.5 \mathrm{~h}$ \\
\hline The maximum theoretical range & $580 \mathrm{~km}$ \\
\hline
\end{tabular}

\section{DESIGN ASSUMPTIONS OF THE PRE- ROTATION SYSTEM}

The system of pre-rotation should allow the gyroplane rotor to spin from $0 \mathrm{rpm}$ to approx. $250 \mathrm{rpm}$. It is also required to transfer the suitable power to the main rotor with respect to the reached revolution per minute. The gyroplane to which this pre-rotation system is dedicated has a two-blade main rotor with a diameter of $8.8 \mathrm{~m}$. The real value of pre-rotation drive power must be sufficient to achieve the required speed in a relatively short period of time. The pre-rotation system should also have the lowest weight and dimensions possible not

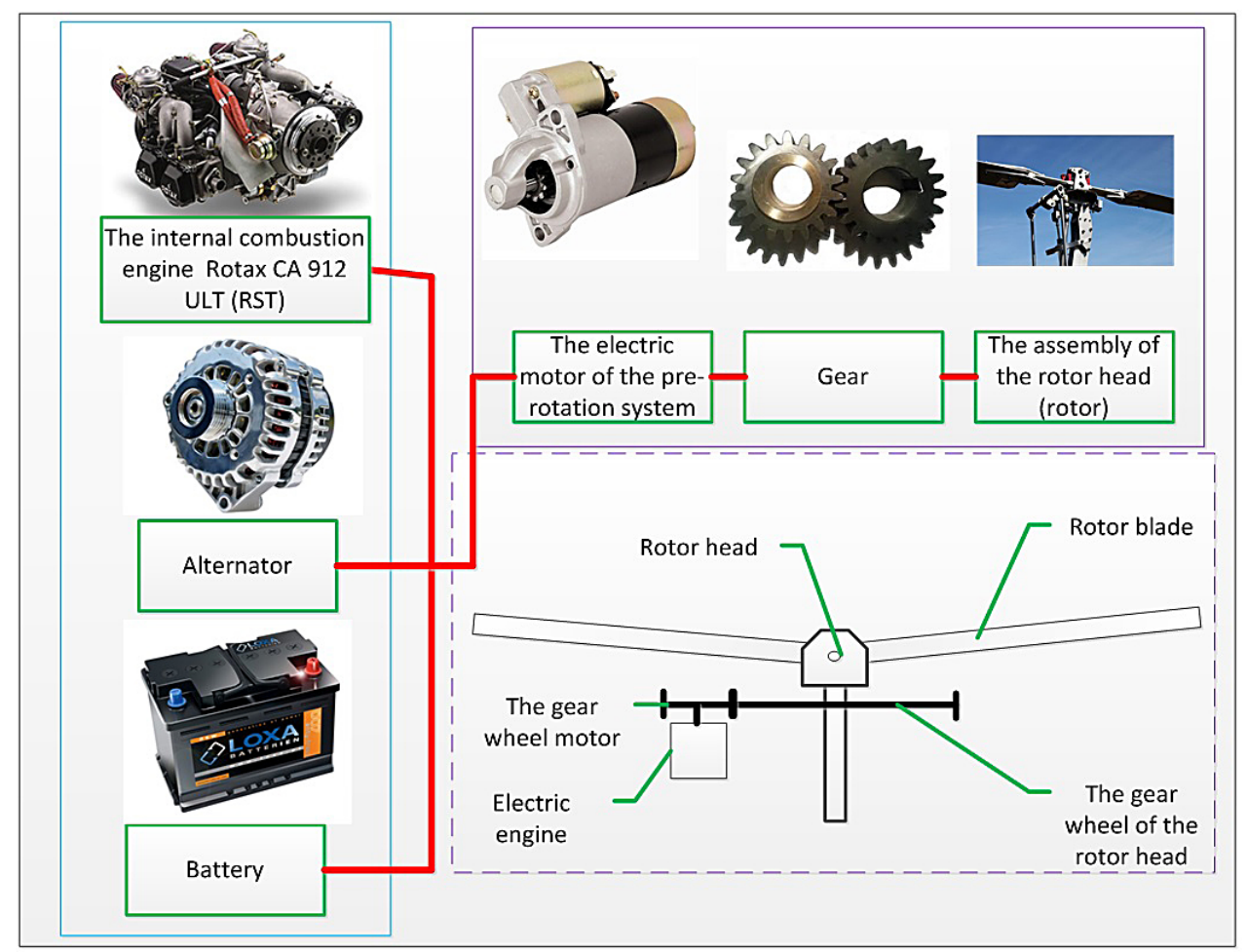

Fig. 2. Schematic of the designed pre-rotation system 


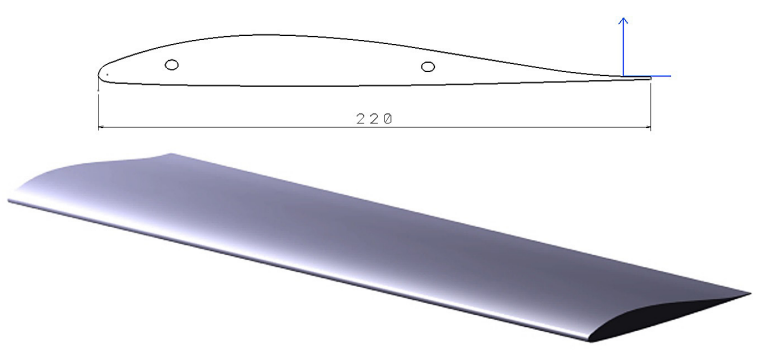

Fig. 3. NACA-9 H-12 airfoil and gyroplane rotor blade based on the NACA-9 H-12 airfoil

to limit the gyroplane during flight. This pre-rotation system cannot interfere with the operation of the rotor. Figure 2 shows a diagram of the proposed pre-rotation system where the electric motor as a starter motor drives with a gear rotor. The starter is powered by electrical energy stored in the battery.
In this paper, our calculations are based on the NACA air-9 H-12 airfoil with a chord equal to 220 $\mathrm{mm}$ which is very popular in gyroplanes. Figure 3 depicts the applied airfoil with a rotor blade (4.4 $\mathrm{m}$ long), the construction of which is based on this airfoil.

Figures 4 and 5 show the characteristics of the applied airfoil drag coefficient as a function of angle of attack for $\operatorname{Re}=2,600,000$ and $R e=1,800,000$.

\section{DETERMINING THE FORCES ACTING ON THE ROTOR DURING PRE-ROTATION}

The main elements of the gyroplane rotor are its blades. The rotor blades during prerotation are driven by the propulsion system.

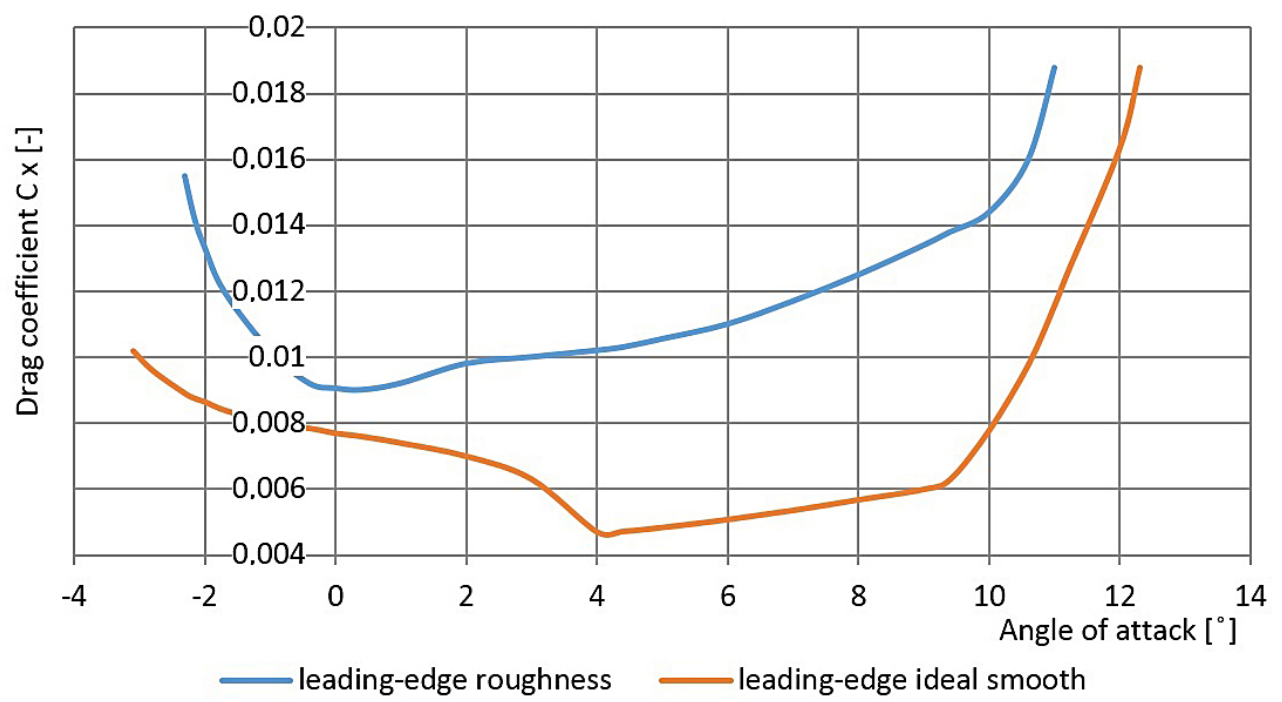

Fig. 4. Characteristics of the drag coefficient as a function of angle of attack for $\operatorname{Re}=2,600,000$. Own elaboration based on [4]

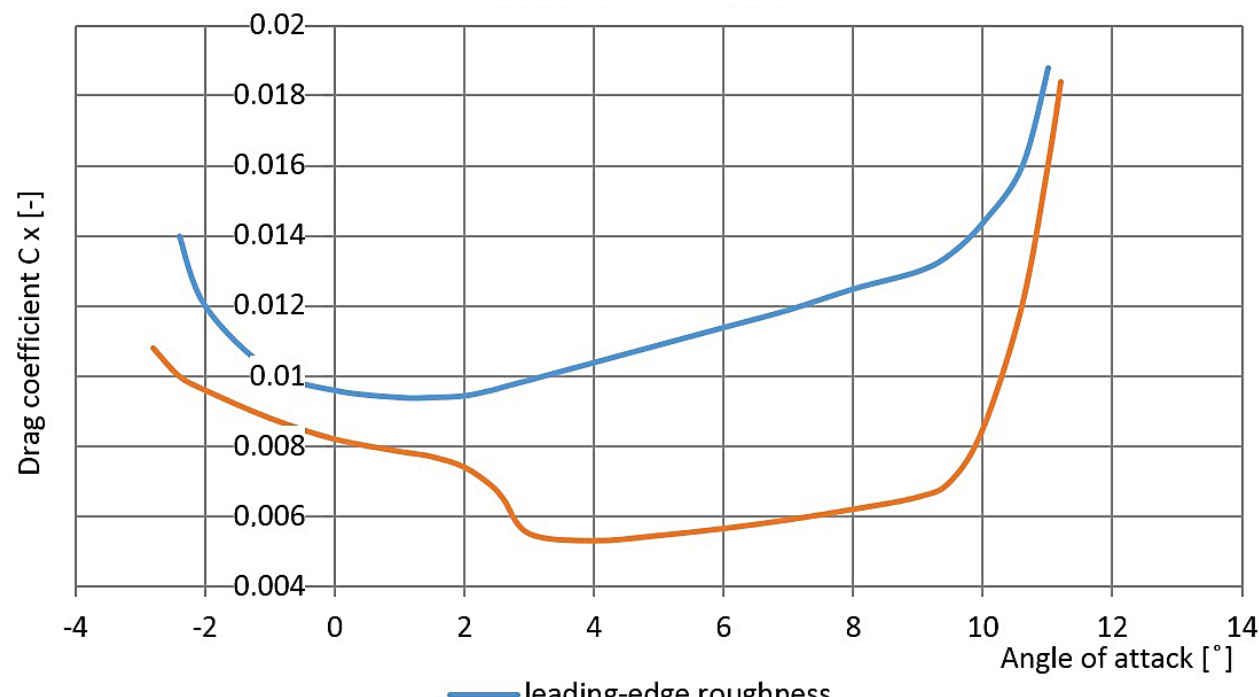

Fig. 5. Characteristics of the drag coefficient as a function of angle of attack for $\operatorname{Re}=1,800,000$. Own elaboration based on [4] 


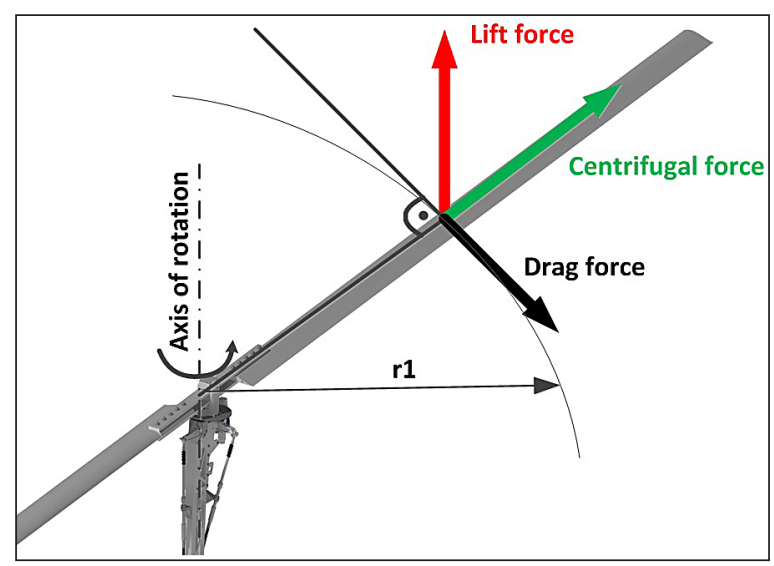

Fig. 6. Diagram of the mass and aerodynamic loads of the rotor blades

Blades due to their fundamental role in the functioning of the rotor are among the most important parts of this assembly. The safety of the whole drive system depends on their strength and durability. The destruction of the blade is usually equivalent to the destruction of the aircraft. During operation, the following stresses are formed in rotor blades $[5,6]$ :

- tensile induced by the centrifugal forces of rotating masses of the blade;

- bending induced by air acting on the part of the airfoil,

- bending induced by the centrifugal forces from the rotating mass of the blade;

- tangent induced by the action of torsional forces induced by the airflow;

- tangent induced by the action of torsional mass forces of the blade;

- bending induced by the transverse vibrations of the blade;

- tangent induced by the torsional vibration of the working part of the blade.

Due to the approved scope of work, it was decided to reduce these loads to those that have a direct effect on pre-rotation and the drive system. Therefore, our further calculations take into account only the load induced by the airflow, namely the drag force. Drag is the force that exerts air or other gas on the body. It results from the movement of the body relative to the air [7]. Figure 6 shows the mass loads (centrifugal) and aerodynamic loads of the rotor blade.

In order to determine the power of pre-rotation needed to spin the rotor, the algorithm in Figure 7 was formulated. Angular velocity

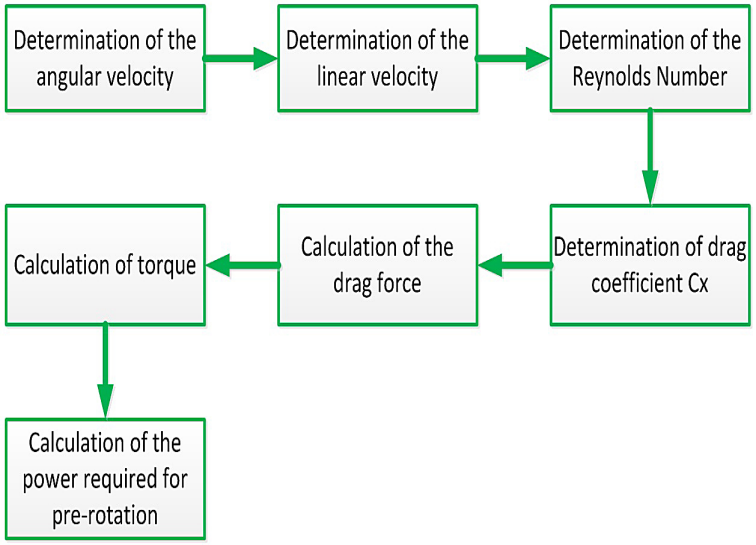

Fig. 7. Algorithm for calculating the power of pre-rotation

$\omega[\mathrm{rad} / \mathrm{s}]$ determined by substituting the value of rotational speed $n$ [rpm] to Equation 1. It is assumed that the drive system should guarantee pre-rotation speed $n=250 \mathrm{rpm}$ then:

$$
\begin{gathered}
\omega=\frac{2 \pi n}{60} \\
\omega=\frac{2 \pi * 250}{60} \cong 26.18\left(\frac{\mathrm{rad}}{\mathrm{s}}\right)
\end{gathered}
$$

In the next step, the linear velocity has been calculated at selected distances from the axis of rotation. This makes it possible to determine distribution of the drag force over the entire length of the blade with the same resolution as the designated speed. To calculate linear velocity $v[\mathrm{~m} / \mathrm{s}]$, Equation 2 is used. By substituting in Equation 2 as already calculated angular velocity and the corresponding values of radius $R[\mathrm{~m}]$ obtained for $R=0.2 \mathrm{~m}$, linear velocity equals to $5.24[\mathrm{~m} / \mathrm{s}]$.

$$
\begin{gathered}
v=\omega R \\
v_{1}=26.18 * 0.2 \cong 5.24\left(\frac{\mathrm{m}}{\mathrm{s}}\right)
\end{gathered}
$$

To determine the drag force of the resultant acting on the blade, the speed was determined at distances of $0.2 \mathrm{~m}$ along the entire length of the blade, i.e. from 0 to $4.4 \mathrm{~m}$. Figure 8 shows a diagram illustrating the approach to calculations of linear velocities according to different lengths of the rotor blade. Linear velocity $v$ assumes a linear relationship and takes the value of $115.19 \mathrm{~m} / \mathrm{s}$ at a predefined required rotational speed $n=250 \mathrm{rpm}$. 


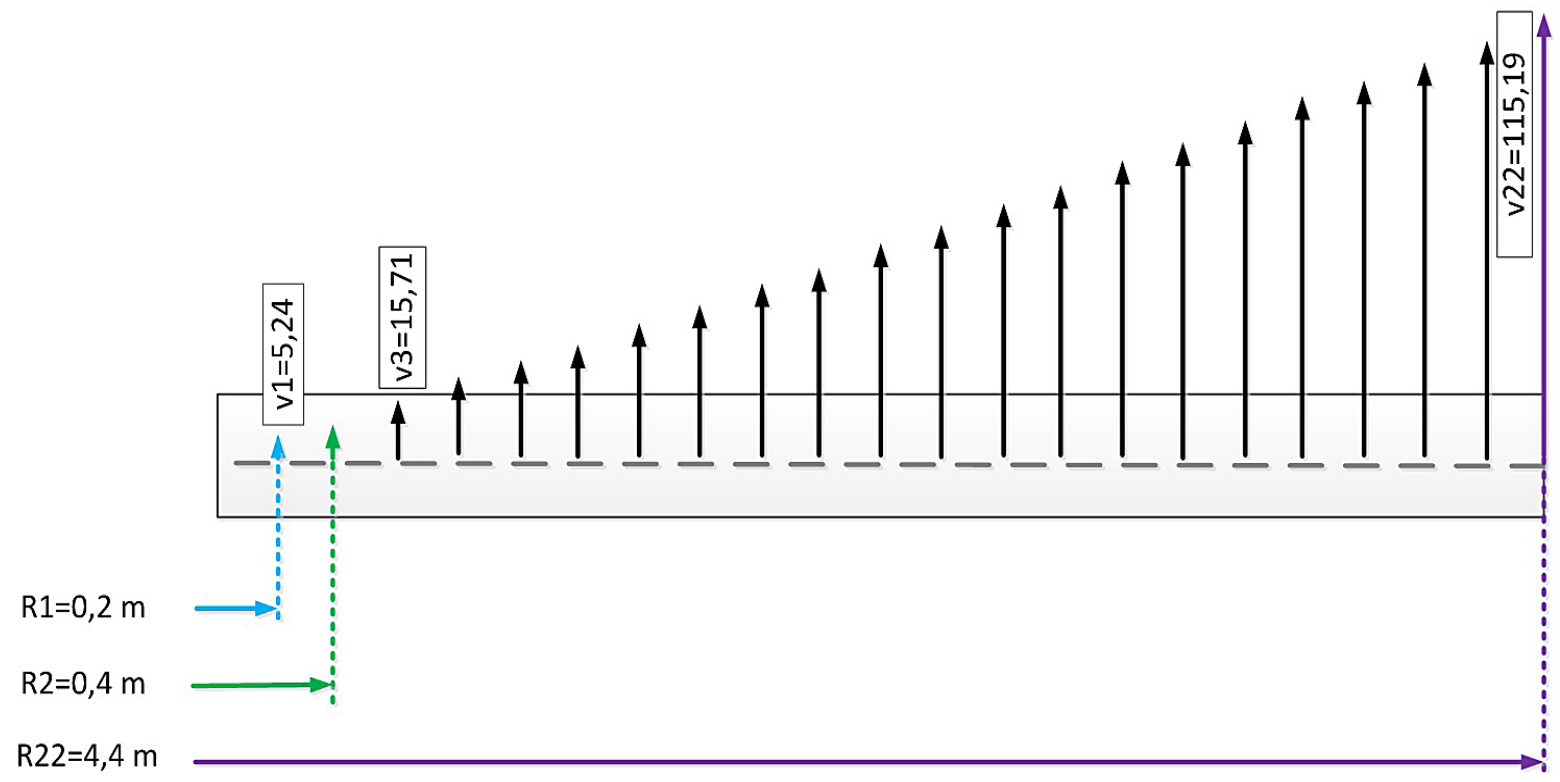

Fig. 8. Linear velocities according to different lengths of the rotor blades

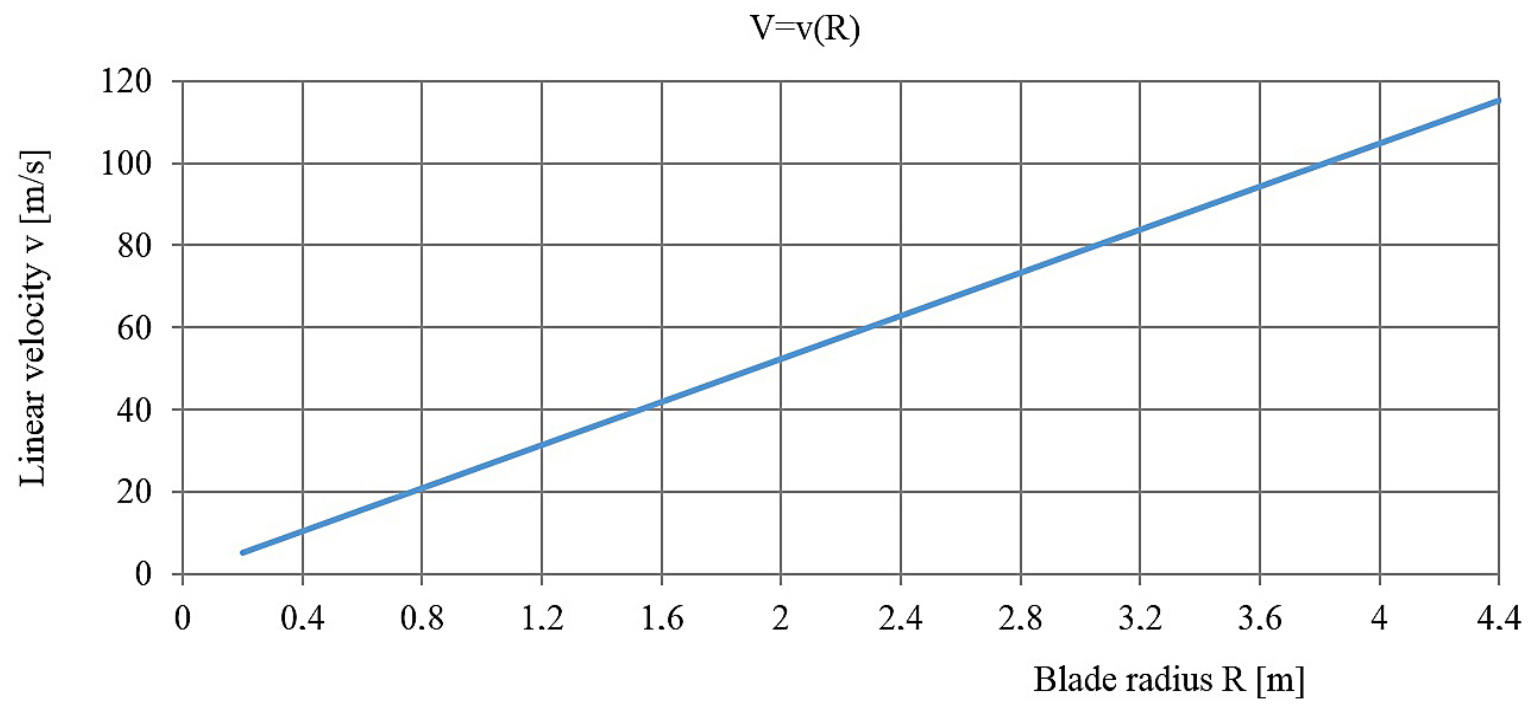

Fig. 9. Results of the calculations of angular and linear velocities

To determine the Reynolds Numbers (3), it is necessary to know air density $\rho$ (working fluid), coefficient of dynamic viscosity $\mu$ and characteristic dimension of the object 1 being to flow around. These values were determined using the fluid properties calculator [8]. The calculations were performed at $20{ }^{\circ} \mathrm{C}$. For this temperature air reaches a density of 1.2047 $\mathrm{kg} / \mathrm{m}^{3}$ and a dynamic viscosity coefficient is $1.8205 \mathrm{e}-5 \mathrm{~kg} /(\mathrm{m} \cdot \mathrm{s})$. For the first one considered, the Reynolds Number for linear velocity v1 equals 69297.38. The values of Re for the other measurement points were calculated in the same way (Figure 10).

$$
\begin{gathered}
\operatorname{Re}=\frac{\rho * v * l}{\mu} \\
\operatorname{Re}=\frac{1.2047 * 5.24 * 0,2}{0.000018205}=69297.38
\end{gathered}
$$

Due to the lower Reynolds Number, drag coefficient $\mathrm{Cx}$ required to calculate the drag force is read from the drag force coefficient characteristic as a function of angle of attack for $\operatorname{Re}=1,800,000$ for the roughened surface of the leading edge and at an angle of attack equal to $2^{\circ}$. Cx for the above conditions is 0.009 . The drag force is described in Equation 4. 


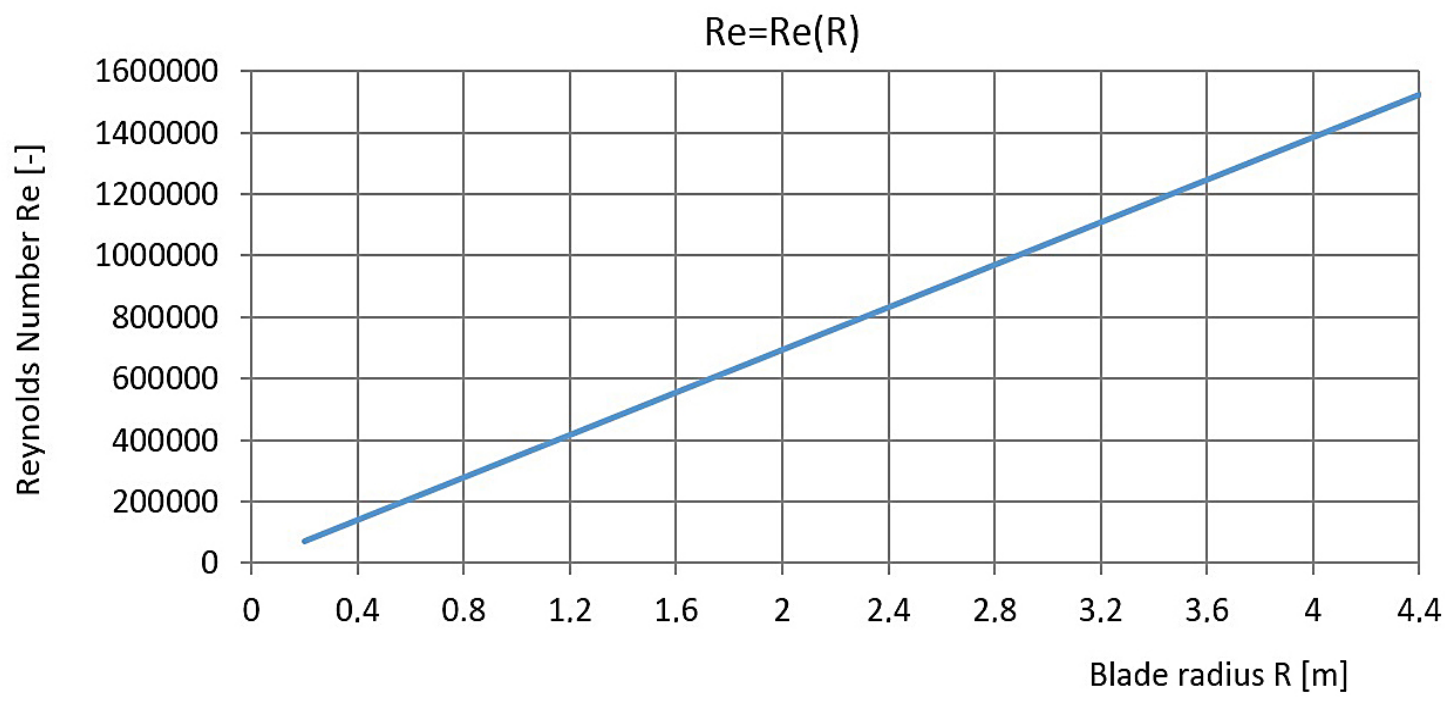

Fig. 10. Reynolds Number for the individual measuring points

$$
D=C_{x} * \rho * S * \frac{v^{2}}{2}
$$

where: $D-$ generated drag force $[\mathrm{N}]$,

$C_{x}-$ drag coefficient [-],

$S$ - the surface area of the airfoil at an angle of blades $\alpha=2^{\circ}\left[\mathrm{m}^{2}\right]$,

$\rho$ - density of air $\left[\mathrm{kg} / \mathrm{m}^{3}\right]$,

$v$ - linear velocity $[\mathrm{m} / \mathrm{s}]$.

For the first calculation point, i.e. for $v=5.24$ and radius $R=0.2 \mathrm{~m}$, drag force $D$ is:

$D=0.009 \cdot 1.2047 \cdot 0.053 \cdot 5.24^{2} / 2=0.01[\mathrm{~N}]$

The results of drag force $D$ for the other calculation points are shown in Figure 11.

Torque $M[\mathrm{Nm}]$ is generated by drag force $D$ described by Equation 5. Figure 12 shows the results of the calculation of the torque generated by the rotor blade.

$$
M=D \cdot R
$$

Power $P[\mathrm{~kW}]$ is needed to drive the pre-rotation described in Equation 5. To obtain a rotational speed $n=250[\mathrm{rpm}]$ for the selected radius $R 1$ where torque $M=0.002 \mathrm{Nm}$, the required power for a drive unit is $0.000043 \mathrm{~kW}$.

$$
P=\frac{M * n}{9549.3}
$$

$$
P=\frac{0.002 * 250}{9549.3}=0.000043
$$

The polynomial designated by the method of least squares (6) describes the change

$\mathrm{D}=\mathrm{D}(\mathrm{R})$

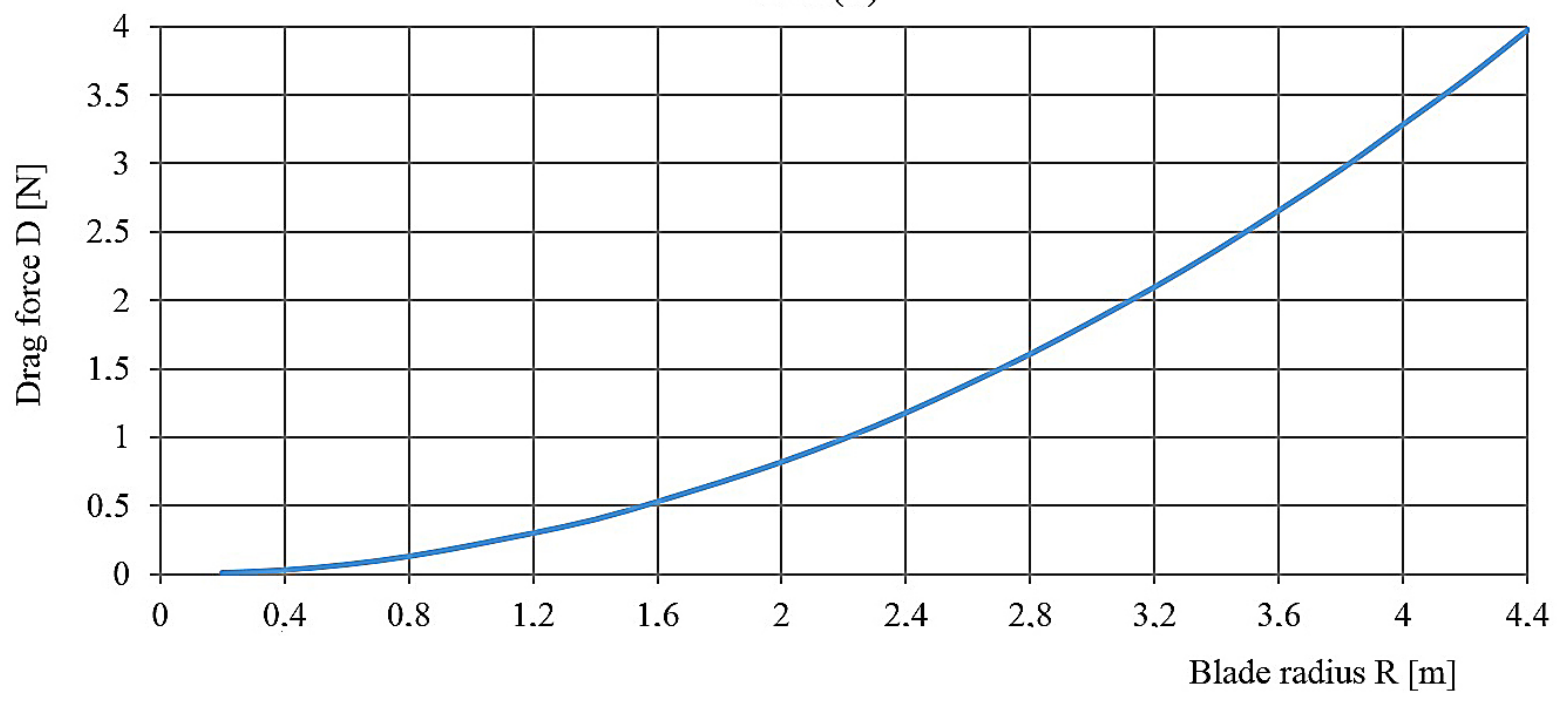

Fig. 11. Drag force for the considered calculation points at $\alpha=2^{\circ}$ 


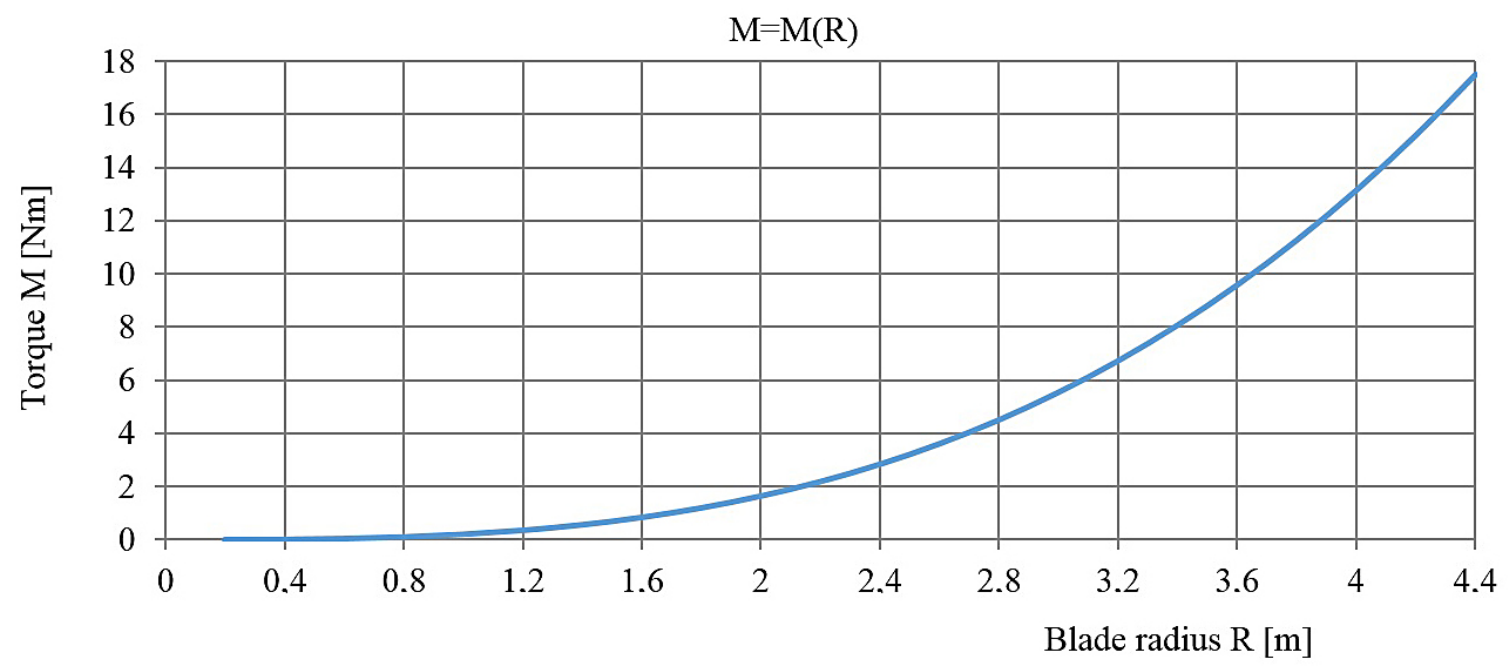

Fig. 12. Results of the calculations of the torque generated by the rotor blade with $\alpha=2^{\circ}$

$$
\begin{gathered}
P(R)=0.00537532418001592 \cdot R^{3}-6.99872258491349 E-8 \cdot R^{2} \\
+1.6721655907568 E-8 \cdot R^{1}-1.02529098523917 E-8 \cdot R^{0}
\end{gathered}
$$

in power value $P$ depending on the blade radius $R$. The maximum deviation value by polynomial approximations of degree 3 is: $-5.307854604817 \mathrm{E}-7$, while the minimum deviation is: $5.98531739350993 \mathrm{E}-9$. The total power resulting from the drive of a single blade rotor was calculated as the sum of the value of the power for the considered blade radii.

According to the above algorithm, the calculations for the speed range of 0 to $400 \mathrm{rpm}$ are made. The dependence of the estimated power required to maintain a certain speed of rotation of the rotor in the TAURUS gyroplane depending on the value of the frequency of rotation is shown in Figure 14.

\section{CONCLUSIONS}

At a speed of $n=250 \mathrm{rpm}$, the power required to drive the single blade rotor is 2.75 $\mathrm{kW}$ or for the double blade rotor is $5.5 \mathrm{~kW}$. The total torque for the same rotational speed is $210.23 \mathrm{Nm}$. This is the torque which drives

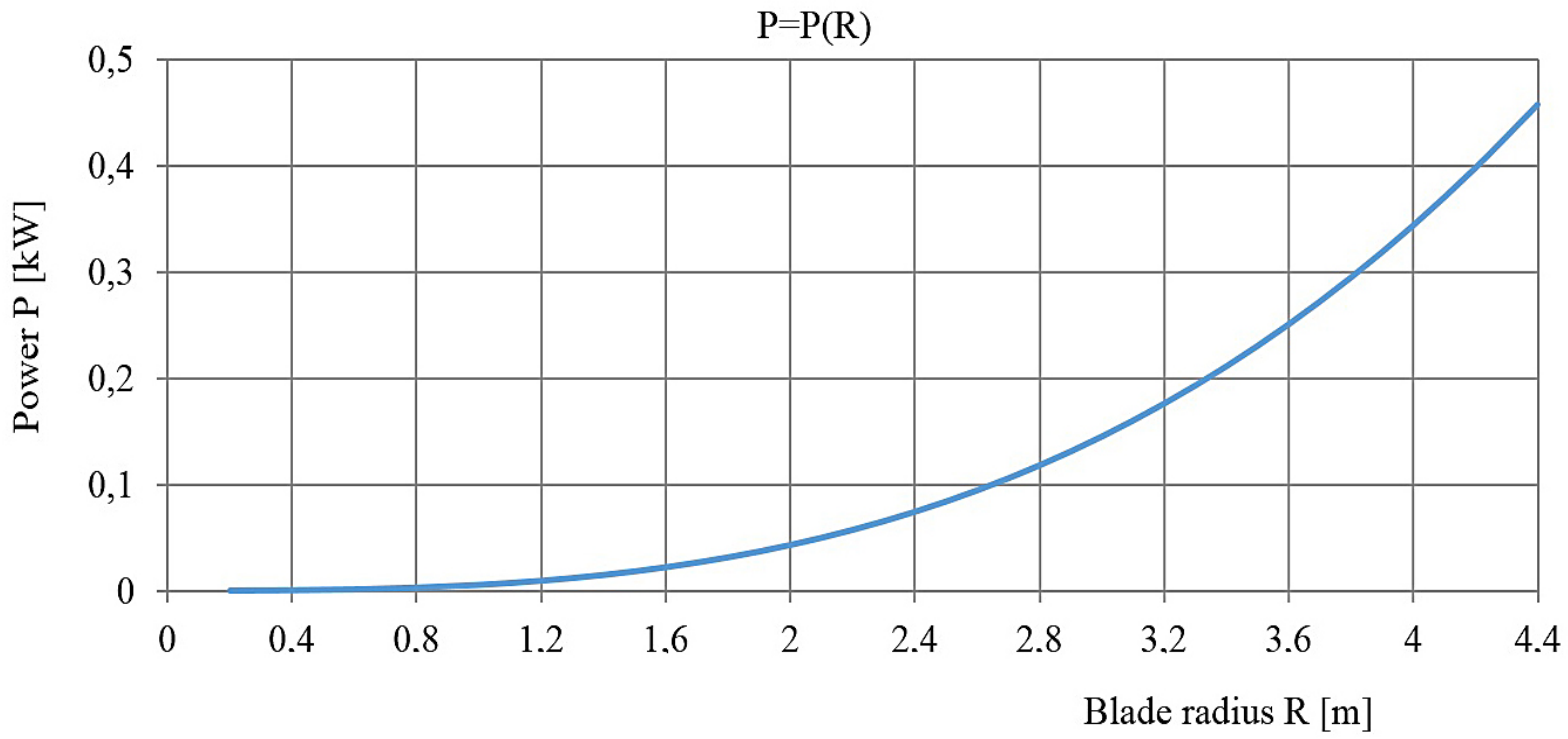

Fig. 13. Results of the calculation power required to obtain a rotational speed $n=250 \mathrm{rpm}$ 


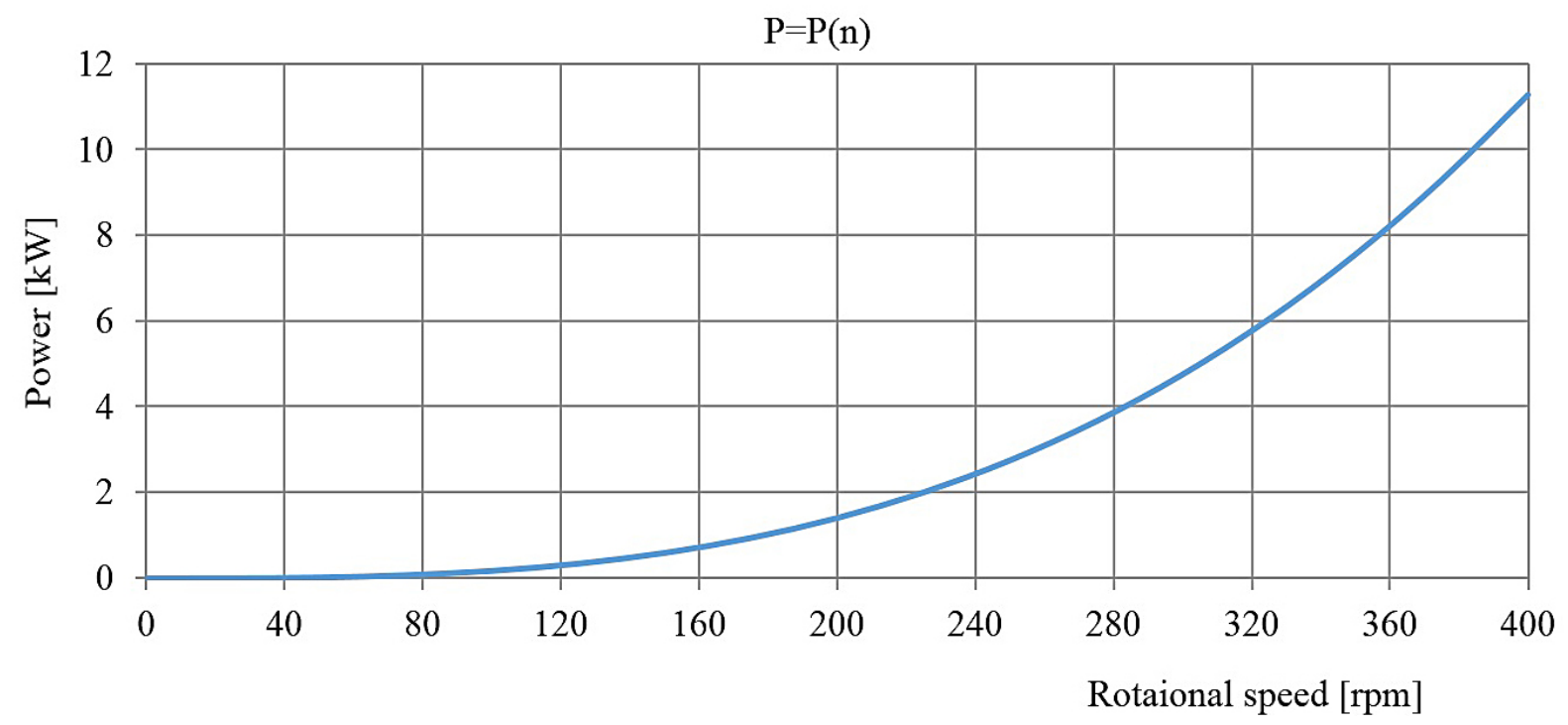

Fig. 14. Power to maintain a certain rotational speed of the TAURUS gyroplane rotor vs. rotational speed $\mathrm{n}[\mathrm{rpm}]$

a rotor under given conditions in the input. For the drive rotor powered by an electric motor or the internal combustion engine coupled to the rotor by gearing, the torque is smaller, which is related to a gear ratio.

\section{REFERENCES}

1. Antkowiak K. Pilotaż - ABC wiatrakowca. Przegląd lotniczy, 9/2011, 2011, 2-5.

2. Delega M., Krzymień W. Weryfikacja rozwiązań prerotacji wirnika wiatrakowca. Prace Instytutu Lotnictwa, 3 (236), 2014, 35-40.
3. http://trendak.eu/models/taurus/tech_data.

4. Stivers S.L., Rice J.F. Aerodynamic characteristic of four Naca airfoil sections designed for helicopter rotor blades, Washington, 1946.

5. Szczeciński S. i in. Zespoły wirnikowe silników turbinowych. WKIt, Warszawa 1982.

6. Lipka J. Wytrzymałość maszyn wirnikowych. WNT, Warszawa 1967.

7. Leishman J.G. Principles of Helicopter Aerodynamics. University of Maryland, College Park, 2006.

8. Fluid Properties Calculator: http://www.mhtl. uwaterloo.ca/old/onlinetools/airprop/airpr. 